\title{
OUTREACH PROGRAMMES FOR EDUCATION AND TRAINING: CONTRIBUTIONS FROM THE INTERNATIONAL CARTOGRAPHIC ASSOCIATION
}

\author{
W. E. Cartwright ${ }^{\mathrm{a}, *}$, D. Fairbairn ${ }^{\mathrm{b}}$ \\ ${ }^{a}$ School of Mathematical and Geospatial Sciences, RMIT University, Australia - william.cartwright@rmit.edu.au \\ ${ }^{\mathrm{b}}$ Dept. of Geomatic Engineering, University College London, Gower Street, London, WC1E 6BT UK - \\ dave.fairbairn@ncl.ac.uk
}

KEY WORDS: Education, outreach, international societies

\begin{abstract}
:
Organisations like the International Cartographic Association champion programmes that develop and deliver education and training to cartographers and geospatial scientists, globally. This can be in the form of traditional university and training college programmes, short courses for professional and technical members of mapping agencies and as outreach initiatives to transfer knowledge about the discipline and its contemporary practices.

Through its international community, the ICA undertakes the transfer of knowledge about cartography and GI Science by publishing books and special editions of journals and running workshops. Colleagues from the ICA community conduct these workshops on a volunteer basis, generally with the support of the national member organisation of ICA or the national mapping body. For example, the ICA promotes the generation of extensive publications, generally through its Commissions and Working Groups. The publications include books, journals and the ICA Newsletter.

Outreach activities are especially pertinent to up skill colleagues from developing countries. Specialist programmes can be offered for professional and 'everyday' map users (from adults to children). The ICA can assist with its current programmes, designed to embrace professional and non-professional cartographers alike.

This paper will address how education and outreach programmes can be supported by international associations, by offering programmes independently, or in partnership with sister associations and national and regional organisations and societies. As well, the paper will address the need to deliver education and outreach programmes not to just the professional international community, but also to map users and citizen map publishers.
\end{abstract}




\section{CHANGES IN INDUSTRY}

The cartographic profession has changed to one that is now supported by contemporary digital production, storage and distribution devices and communication resources. What also has changed are the organisations that conduct mapping programmes and 'build' repositories of geographical knowledge, digital and material. Long gone are the days of large governmental mapping agencies that had their 'tried and true' methods of data capture, processing and dissemination. Today is the workplace of small government agency; contractors (large and small); regional, national and global publishing collaborations; and map producer / user.

As well, there are now new players in geospatial information provision whereby consumer electronics companies like Nokia have purchased mapping companies. As well as Google wanting to enhance its advertising potential and MicroSoft its profile in computer software through a Web presence, other players are now also part of the geospatial industry. For example, TeleAtlas was purchased by TomTom and Navteq was acquired by Nokia. The potential of enhancing consumer electronics with geographical information is now evident in advertising about what these devices can now do.

Another change for cartography is the fact that now the amateur map publisher is now a map provider as well as traditional publishers. Collaboration via Web 2.0 (the use of Social software for personal publishing) allows users to produce maps as mash-ups, which combine already available maps and satellite imagery and overlay their own data. Base maps or satellite imagery is 'mashed' together with pre-existing geospatial artefacts. There are a number of social, collaborative organisations, for example, OpenStreetMap, that make their data and maps available for free. Through a network of Webconnected amateur and professionals geographical data is collected, scripts marked-up with data attributes, data placed in repositories and maps published.

Everything has changed, but the underlying need for useful (and usable), accurate and timely geospatial products remains as the essential underpinnings for what we do.

In order to ensure that both the professional and amateur map producer/user are attuned to the issues related to contemporary cartography it is essential that appropriate educational programmes be provided, face-to-face and on-line.

\section{INTERNATIONAL CARTOGRAPHIC ASSOCIATION}

\subsection{General background}

The International Cartographic Association is the world authoritative body for cartography, the discipline dealing with the conception, production, dissemination and study of maps. The ICA was founded on June 9, 1959, in Bern, Switzerland. The first General Assembly was held in Paris in 1961.

The activities of the ICA are important for promoting and advancing the theory and praxis of cartography. Throughout its 50-year history, ICA has brought together researchers, government mapping agencies, commercial cartographic publishers, software developers, educators, earth and environmental scientists, and those with a passion for maps.
The mission of the International Cartographic Association is to promote the discipline and profession of Cartography and GIScience in an international context.

The ICA has a number of aims:

- To contribute to the understanding and solution of world-wide problems through the use of cartography in decision-making processes;

- To foster the international dissemination of environmental, economic, social and spatial information through mapping;

- To provide a global forum for discussion of the role and status of cartography;

- To facilitate the transfer of new cartographic technology and knowledge between nations, especially to the developing nations;

- To carry out or to promote multi-national cartographic research in order to solve scientific and applied problems;

- To enhance cartographic education in the broadest sense through publications, seminars and conferences; and

- To promote the use of professional and technical standards in cartography.

\subsection{Education and the ICA Strategic Plan}

The ICA's Strategic Plan (ICA, 2010) proposes a number of actions related to Ideas and Actions for the Organisation and in the Wider Operational Environments. Some of these actions that relate to education and capacity-building are:

In education:

- To analyse existing university curricula in Cartography and GI Science, and encourage promotion of the goals contained in the ICA mission.

- To help widen the Cartographic/GIScience knowledge base and skills into new segments of Society

- To increase efforts directed to capacity-building, especially in developing countries, especially with reference to human resource development

- In co-operation with commercial suppliers, to develop virtual academy courses on Cartography and GIScience to support and complement what is currently available.

- To provide geospatial data for educational use.

- To establish a network of university/school teachers to provide a forum for discussion and the possibility for support.

- To extend travel awards for young scientists; lower conference participation fees for students.

In professional practice:

- Organization of workshops on specific topics.

- Organize high quality technical exhibitions and expert panels during the congresses to attract practitioners to participate.

- Encourage national associations and universities to translate outcomes of congresses and symposia into local languages, publish the translations on the web and link them to the ICA page.

- Facilitate the exchange of experts between and within In society: developed and developing countries.

- Atlas production on specific global themes.

- Provide guidelines on the use and presentation of geospatial data on the Internet. 
- Develop navigation tools for visually impaired people.

- Participate in research and development projects aimed at personal security, public services and wellbeing.

- Collect funds from donors in order to organise expert support for developing countries and for developing regions within nation states.

- Support United Nations by providing geospatial expertise.

The Strategic Plan notes that the profession is changing and that the amateur cartographer needs to be considered. It notes: "Amateur and professional practice within the Geospatial sciences will change in nature, increasing the necessity for Continuing Professional Development".

The ICA addresses these and other issues through direct ICA initiatives through its Executive and member organisations and with partners from ICA affiliates, sister societies and industry. The activities of Commissions and Working Groups and programmes provide the 'powerhouse' that supports these endeavours.

Following these goals, the ICA can assist in the delivery of appropriate courses by 1) Assessing the availability of programmes, 2) delivering education courses directly, 3) providing support materials and publications and 4) providing outreach support for developing nations.

\section{CHANGING FACE OF CARTOGRAPHY}

As well as programmes to 'main stream' cartography and GI Science, as organised citizen mapping undertaken (globally) by the organisations like OpenStreetMap, where individuals and groups- everyday citizens - use GPS enabled consumer electronics to undertake mapping. Generally, they are using the software and concepts delivered by Web 2.0.

Crawford (2006) wrote that computers are being used differently with Web 2.0. This illustrates a shift from the conventional publishing model. She writes: "But what has changed over the past 15 years is that they (the users) no longer represent the only way to produce and distribute creative work. As computing power has become more affordable and software has become more powerful, the creative potential of what can be done at home - and at relatively low cost - has soared. And there has been an explosion of creative production as a response. It has been described as "mass amateurisation": the masses now have greater access to the means of cultural production. We are witnessing a crucial shift as the gap narrows between what can be done at home and what is professionally produced; amateur productions take on professional approaches and professional productions make use of the amateur aesthetic." (Crawford, 2006, p. 23). She goes on to say: Everyone is making something, collaborating on something or distributing something. It doesn't matter if it's a zine, a new media installation, a piece of software, an album, a short film or a photo blog" (Crawford, 2006, p. 23).

When using the Web for map publishing quality was adjudged by speed of delivery, circulation figures and screen resolution. Quality was gauged by how the 'rules' of computers and communications systems were applied. Users were still seen as consumers, and not collaborators in geographical knowledge acquisition. The use of Web2.0 as a means for providing geographical information presents different problems for assuring quality. Problems might arise with a conglomerate product related to 'self-constructed' Web 2.0 products. For conventional cartographic products these assurances are provided by cartography. A major issue if self-composed products are to be used with confidence might well be quality assurance. Therefore, methods would need to be developed for assuring quality with conglomerate products, assuring quality with user-produced products and the means for informing users about the source of conglomerate information resources.

There is a need to ensure that these non-traditional mapmakers are attuned to the needs and standards related to contemporary mapping. The ICA has recognised the growing number of nonprofessional mapmakers and has formed a new Commission on Neo-Cartography. This Commission will actively encourage links between traditional and neo-cartographers.

\section{EDUCATIONAL PROGRAMMES}

The ICA has investigated the possibility of offering courses and programmes on-line, via discrete media (CD-ROM) and via conventional paper products. This investigation was undertaken by the ICA Education Commission, in association with other Commissions and Working Groups.

Also through its Education and Training Commission the ICA has developed a virtual course on Cartography and GIScience in collaboration with contributions from universities and individual academics. Users of this Web-delivered resource can assemble a hybrid course. The courses can be accessed via the Commission Web site at: http://lazarus.elte.hu/cet/.

In the future this concept could be expanded to include various implementation levels, which could be:

- $\quad$ ICA designed and delivered

- $\quad$ ICA designed and Commission-delivered

- Commission designed and delivered

- Working Group designed and delivered

- Delivered by Universities with ICA endorsement and branding

- Delivered by organisations or companies with ICA endorsement and branding

\section{OUTREACH}

The ICA has always championed outreach programmes. In particular, the Association has a Working Group entitled 'mapping Africa for Africa'. However, we need to extend our role in Australasia and Oceania to extend the activities to nations who are not yet members. When we look at a map of member nations of the ICA, Pacific nations, in particular, are missing.

For Australasia exists national cartographic organisations in Australia and New Zealand that are members of the ICA. These organisations have as their core activities to progress the professional, academic and scientific status of all working in the geospatial professions. We need to ensure that Pacific nations gain benefit from belonging to ICA. We need to champion extended ICA representation in the Oceania region and to promote activities and events in Cartography and Geographic Information Science that occur in the region

We can do this by: 
- Forming a regional consortia to champion cartographic activities (these can be both physical and (virtual);

- Championing activities and alliances that advance cartographic knowledge in the region;

- Encouraging nations to participate in ICA activities, both at a regional and international level;

- Disseminating information at conferences, through the provision of books, journals, educational programmes, outreach programmes like workshops and perhaps a cartographic 'roadshow';

- Organising a regional cartographic conference / event (perhaps in conjunction with the UN Asia-Pacific Regional Cartographic conference), linked to either an Australian a New Zealand, or a Trans-Tasman initiative to 'kick-start' such an event, but 'owned' by the region and offered / operated by contributing nations); and

- Eliciting journal papers that provide regionallyfocussed information (on topics that range from historical, to practical / production, to cultural to research).

Some examples of activities that support outreach programmes are provided in the following sections.

\subsection{Young Scientists awards}

At each ICA conference the Association makes available Travel Awards for young scientists to attend and present. In 2009 seven awards were made for travel to the ICA conference in Santiago, Chile. Young scientists from Ukraine, China, Poland, Chile, Brazil, Argentina and Senegal attended the conference and presented papers under this scheme.

\subsection{Graduate students' seminars}

At the first ICA Symposium on Cartography and GIScience for Central and Eastern Europe, in Vienna, Austria, in February 2009 included a special session where junior scientists presented their research work in a dedicated $\mathrm{PhD} /$ Master Forum. PhD students presented the results of their research and a panel of experienced researchers provided feedback to student presenters.

\subsection{Research resources for young scientists}

The ICA Commission on Use and User Issues has established an online bibliography on use and user issues to support young researchers. Young researchers also form a very important target group for the handbook on user research methods and techniques the Commission is currently working on. Research knowledge flow is not just one-way: young PhD researchers also share their knowledge with others by contributing to the development of the handbook.

\subsection{Commissions and Working Groups outreach activities}

To achieve its aims the ICA operates through a number of Commissions and Working Groups. Commissions and Working Groups carry out the general operations of the ICA. These organisations have addressed the full range of scientific, technical and social research that is the mark of ICA activity. They achieve the transfer of knowledge about Cartography and GIScience and GI Science by publishing books and special editions of journals and running workshops. Colleagues from the ICA community conduct these workshops on a volunteer basis, generally with the support of the national member organisation of ICA or the national mapping body.

\section{WORKING WITH SISTER SOCIETIES}

Sister organisations that form the Joint Board of Geospatial Information Societies champion education and training. The Joint Board of Geospatial Information Societies is a coalition of leading international geospatial societies that speaks on behalf of the geospatial profession at the international level, especially to the United Nations and other global stakeholders. It coordinates activities within the geospatial society and organizations, internationally.

This can be in the form of traditional university and training college programmes, short courses for professional and technical members of mapping agencies and as outreach initiatives to transfer knowledge about the discipline and its contemporary practices.

These programmes can be supported by Associations offering programmes independently, or in partnership with sister associations. As well, access to associations' publications, paper or Web-delivered, can be used to support such activities.

\section{CONCLUSION}

In conclusion, international organisations like the International Cartographic Association must be realistic about our contributions to international professional and amateur communities. We can't contribute to all efforts. We need to work with our strengths. We must promote cartographic events and educational programmes internationally and regions, especially considering regional needs and endeavours in what we do.

\section{REFERENCES}

Crawford, K., 2006. Oh grow up!. Edited extract from the book Adult Themes: Rewriting the Rules of Adulthood, Macmillan Australia, in The Age Good Weekend, September 23, 2006, pp $18-23$.

ICA (2003). "Strategic Plan"

http://www.icaci.org/documents/reference_docs/ICA_Strategic Plan_2003-08-16.pdf 